\title{
Correction to: Construction robotics for designed granular materials: in situ construction with designed granular materials at full architectural scale using a cable-driven parallel robot
}

\author{
Karola Dierichs $^{1}$ D $\cdot$ Ondřej Kyjánek ${ }^{1} \cdot$ Martin Loučka $^{1} \cdot$ Achim Menges $^{1}$
}

Published online: 16 November 2019

๑) Springer Nature Switzerland AG 2019

\section{Correction to: Construction Robotics \\ https://doi.org/10.1007/s41693-019-00024-6}

The original version of this article unfortunately contained mistakes. The conflict of interest was incorrect. The corrected conflict of interest is given below.

Conflict of interest Karola Dierichs and Achim Menges hold a patent application (DE102012100334A1) which is related to this research. Other than that there are no competing interests. 